\title{
Kinetics of Esterification of Palmitic acid with Ethanol- Optimization Using Statistical Design of Experiments
}

\author{
C. Beula and P. S. T. Sai
}

\begin{abstract}
The aim of this study was to apply statistical design of experiments for optimization of esterification reaction and to obtain the kinetics of the reaction. The present system of study was palmitic acid with ethanol using homogeneous catalyst sulphuric acid. The reactions were performed in a batch reactor and the progress of the reaction was monitored using Karl Fischer Titrator. To reduce the number of experiments and in order to achieve optimum conditions of the reaction, statistical design of experiments was carried out. Using Box- Behnken response surface analysis with three factors, three central points and one block, a table was designed with 15 experiments. The variable influencing the rate of reaction are temperature, mole ratio of reactants and catalyst concentration. The conversion is complete at a temperature of $73^{\circ} \mathrm{C}$, initial molar ratio of reactants of 9.39 and at a catalyst concentration of $6.4 \mathrm{wt} \%$. Integral method of analysis was used to analyze the batch reactor data and the order of the reaction was obtained. The reaction rate constants, frequency factor and activation energy of the reaction were determined.
\end{abstract}

Index Terms-Box-behnken design, esterification reactions, design of experiments, kinetics.

\section{INTRODUCTION}

The synthesis of carboxylic acid esters is an industrially important operation because of its application in vast areas ranging from domestic use to food industry [1]-[7]. Organic esters can be synthesized by different methods. The most important method is the direct reaction of organic acid with alcohol in the presence of acid catalyst [1]. As esterification reactions are very slow and reversible, it requires several days to reach equilibrium in the absence of catalyst. The acid catalysts include $\mathrm{H}_{2} \mathrm{SO}_{4}, \mathrm{HCl}, \mathrm{HI}$ and some strong organic acids [2]. Generally esterification is carried out in the presence of sulphuric acid as catalyst because of its high acid strength. This acid strength is responsible for the release of $\mathrm{H}^{+}$ions and thereby protonate the caboxilic acid [3].

The present work is concentrated on the production of ethyl palmitate, which is an important organic ester produced by the esterification of palmitic acid with ethanol in the presence of sulphuric acid as catalyst.

Palmitic acid $(A)+$ ethanol $(B) \leftrightarrow$ ethyl palmitate $(C)+$ water $(D)$

This ethyl palmitate ester has a soft and waxy odour and is used to give fragrance to saffron, cream, vanilla and flavors

Manuscript received July 12, 2013; revised September 16, 2013.

The authors are with the Department of Chemical Engineering, Indian Institute of Technology Madras, Chennai-600036, India (e-mail: beulaprasoon@gmail.com,psts@iitm.ac.in). of milk, fish etc. For the large scale production of ethyl palmitate reaction kinetics should be well determined [2]. Usually rate of reaction is influenced by many factors such temperature of reaction, initial mole ratio of reactants, type of catalyst, catalyst concentration and mechanical agitation rate etc. Among these variables temperature of the reaction mixture, initial mole ratio of reactants and catalyst concentration were chosen and the other two parameters were kept constant for the entire study. Here an attempt is made to correlate the variables with the yield through a statistical design tool and trying to develop kinetics model of palmitic acid esterification reaction.

\section{MATERIAL AND METHODS}

\section{A. Chemicals}

All chemicals used for this study were analytical grade. Hexadeconoic acid (99-101.0\%) supplied by S.D. Fine Chem Limited, ethyl alcohol (99.9 wt \%) purchased from Jiangsu Huaxi International and concentrated sulphuric acid (98 wt \%) from RFCL limited were used for the reaction. Karl Fischer Solution (Merck Specialties Pvt. Limited) and methanol (99.8 wt\% HPLC grade, Thomas Baker) were used for the analysis.

\section{B. Analysis}

The reaction samples collected at different interval time were analyzed by Karl Fischer Titrator (Metrohm $870 \mathrm{KF}$ Tritino plus, Switzerland), which gives the water content of the samples. The Karl Fischer Titrino is an automated titration system that carries out the titration automatically and it produces results very rapid and precisely. The whole assembly constitutes Metrohm $870 \mathrm{KF}$ Titrino plus, $803 \mathrm{Ti}$ Stand and $100 \mathrm{ml}$ capacity KF titration cell with magnetic stirrer.

\section{Statistical Design of Experiments}

Statistical design of experiment is a tool commonly used to reduce the total number experiments for obtaining best overall optimization of the system. It is also useful for the modeling of the system response which is affected by many variables [8]. The analysis well describes the effect of these variables on the response. In the present study the BoxBehnken experimental design of response surface methodology (RSM) has been chosen to determine the relationship between the percentage conversion and operating variables [9]-[12]. The factors in these experiments are temperature of reaction system $\left(X_{1}\right)$, mole ratio of initial reactants $\left(X_{2}\right)$ and catalyst concentration $\left(X_{3}\right)$ and the 
percentage conversion of the reactants or yield of the product is the response $(Y)$. A second order polynomial model (Eq.1) is used to correlate the response $\mathrm{Y}$ and the three independent variables $X_{1}, X_{2}$ and $X_{3}$ as

$$
\begin{aligned}
Y= & a_{0}+a_{1} X_{1}+a_{2} X_{2}+a_{3} X_{3}+a_{11} X_{11}+a_{22} X_{22}+a_{33} X_{33}+a_{12} X_{1} X_{2} \\
& +a_{13} X_{1} X_{3}+a_{23} X_{2} X_{3}
\end{aligned}
$$

where $a_{0}$ is a constant, $a_{1}, a_{2}$ and $a_{3}$ are the coefficients of linear effect, $a_{11}, a_{22}$ and $a_{33}$ are quadratic coefficients and $a_{12}$, $a_{13}$ and $a_{23}$ are the coefficients of interaction between the variables.

\begin{tabular}{|c|c|c|c|c|c|c|c|}
\hline \multirow{2}{*}{$\begin{array}{l}\text { Experiments } \\
\text { Sl.No. }\end{array}$} & \multicolumn{3}{|c|}{ Coded form } & \multicolumn{3}{|c|}{ Un-coded form } & \multirow{2}{*}{$\begin{array}{l}\text { Yield } \\
\text { Y\% }\end{array}$} \\
\hline & $\mathrm{x}_{1}$ & $\mathrm{X}_{2}$ & $\mathrm{x}_{3}$ & $\mathrm{X}_{1}$ & $\mathrm{X}_{2}$ & $\mathrm{X}_{3}$ & \\
\hline 1 & -1 & -1 & 0 & 65 & 5 & 5 & 79.04 \\
\hline 2 & 1 & -1 & 0 & 75 & 5 & 5 & 81.59 \\
\hline 3 & -1 & 1 & 0 & 65 & 10 & 5 & 93.51 \\
\hline 4 & 1 & 1 & 0 & 75 & 10 & 5 & 97.01 \\
\hline 5 & -1 & 0 & -1 & 65 & 8 & 3 & 65.30 \\
\hline 6 & 1 & 0 & -1 & 75 & 8 & 3 & 68.13 \\
\hline 7 & -1 & 0 & 1 & 65 & 8 & 7 & 93.38 \\
\hline 8 & 1 & 0 & 1 & 75 & 8 & 7 & 99.00 \\
\hline 9 & 0 & -1 & -1 & 70 & 5 & 3 & 60.00 \\
\hline 10 & 0 & 1 & -1 & 70 & 10 & 3 & 70.00 \\
\hline 11 & 0 & -1 & 1 & 70 & 5 & 7 & 87.10 \\
\hline 12 & 0 & 1 & 1 & 70 & 10 & 7 & 98.00 \\
\hline 13 & 0 & 0 & 0 & 70 & 8 & 5 & 94.00 \\
\hline 14 & 0 & 0 & 0 & 70 & 8 & 5 & 94.04 \\
\hline 15 & 0 & 0 & 0 & 70 & 8 & 5 & 92.50 \\
\hline \multirow{2}{*}{\multicolumn{4}{|c|}{ Factors }} & \multicolumn{4}{|c|}{ Levels } \\
\hline & & & & -1 & 0 & 1 & \\
\hline \multicolumn{4}{|c|}{$\mathrm{X} 1$, Temperature ${ }^{\circ} \mathrm{C}$} & 65 & 70 & 75 & \\
\hline \multicolumn{4}{|c|}{$\mathrm{X} 2$, Initial mole ratio of reacatnts } & 5 & 8 & 10 & \\
\hline \multicolumn{4}{|c|}{$\mathrm{X} 3$, Catalyst concentration, wt $\%$} & 3 & 5 & 7 & \\
\hline
\end{tabular}

TABLE I: BOX-BEHNKEN EXPERIMENT DESIGN

Box- Behnken design of RSM with three factors at three levels, three central points and one block was chosen to design the experimental design table using Minitab 16 statistical software. This Box- Behnken design requires a fifteen set of experiments for the precise prediction of the model relating the response and parameters as shown in Table I.

\section{Experimental Procedure}

Experiments were conducted in a batch reactor, which is surrounded by a Perspex jacket. Water at constant temperature from a thermostat is circulated through this jacket. The reactor is a flat bottomed flask of $250 \mathrm{ml}$ capacity with magnetic agitation. Calculated quantity of ethanol (1 $\mathrm{mol}$ ) is placed in the reactor. At zero time, known quantity of palmtic acid which is separately heated to the set temperature and calculated amounts of sulfuric acid were added into the reactor. Constant stirring speed of $600 \mathrm{rpm}$ was maintained throughout the experiment. Pipetted out samples at different intervals of time and the amount of water present in the samples were measured by Karl Fischer Titrator. The progress of reaction was monitored by following the concentration of water. The experiments were conducted based on the design table (Table I).

\section{RESULTS AND DISCUSSION}

\section{A. Box-Behnken Response Surface Design}

The experiments were carried out as per the design Table I. The experimental data were fitted with a second order polynomial model given by Eq.1. The coefficients of the model (full quadratic) in uncoded term, $t$ value and $p$ value of the analysis are given in Table II.

TABLE II: ESTIMATED REGRESSION COEFFICIENT, T AND P VALUE OF BOX-BEHNKEN DESIGN USING FULL QUADRATIC MODEL

\begin{tabular}{cccccc}
\hline \multirow{2}{*}{ Term } & $\begin{array}{c}\text { Coefficient } \\
\text { in uncoded } \\
\text { term }\end{array}$ & $\begin{array}{c}\text { Standard } \\
\text { Error(SE) } \\
\text { coefficient }\end{array}$ & $t$ value & $p$ value & $\begin{array}{c}\text { Signifance } \\
\text { level }(1-p) \%\end{array}$ \\
\hline Constant & -352.879 & 179.098 & -1.97 & 0.11 & $>89$ \\
$X_{I}$ & 8.407 & 4.960 & 0.70 & 0.15 & $>84$ \\
$X_{2}$ & 11.069 & 5.244 & 2.11 & 0.09 & $>91$ \\
$X_{3}$ & 28.250 & 6.429 & 4.39 & 0.01 & $>99$ \\
$X_{11}$ & -0.061 & 0.035 & -1.74 & 0.14 & $>85$ \\
$X_{22}$ & -0.672 & 0.140 & -4.79 & 0.01 & $>99$ \\
$X_{33}$ & -2.634 & 0.219 & -12.01 & 0.00 & $>99$ \\
$X_{12}$ & 0.019 & 0.067 & 0.28 & 0.79 & $>21$ \\
$X_{13}$ & 0.070 & 0.084 & 0.83 & 0.45 & $>55$ \\
$X_{23}$ & 0.045 & 0.169 & 0.27 & 0.80 & $>20$ \\
\hline
\end{tabular}

TABLE III: ESTIMATED REGRESSION COEFFICIENT, T AND P VALUE OF BOX-BEHNKEN DESIGN USING LINEAR + SQUARE MODEL

\begin{tabular}{lcccccc}
\hline \multicolumn{5}{c}{ Term } & \multicolumn{3}{c}{ coefficients } & & & \\
\cline { 2 - 5 } & $\begin{array}{c}\text { un-coded } \\
\text { term }\end{array}$ & $\begin{array}{c}\text { coded } \\
\text { term }\end{array}$ & $\begin{array}{c}\text { Standard } \\
\text { Error(SE) }\end{array}$ & $t$ value & $p$ value & $\begin{array}{c}\text { Significance } \\
\text { level (\%) }\end{array}$ \\
\hline$a_{0}$ & -388.954 & 93.513 & 147.705 & -2.63 & 0.03 & $>97$ \\
$X_{I}$ & 8.898 & 1.813 & 4.198 & 2.12 & 0.07 & $>93$ \\
$X_{2}$ & 12.624 & 6.349 & 1.810 & 6.97 & 0.00 & $>99$ \\
$X_{3}$ & 33.470 & 14.256 & 1.891 & 17.70 & 0.00 & $>99$ \\
$X_{11}$ & -0.061 & -1.524 & 0.030 & -2.03 & 0.08 & $>92$ \\
$X_{22}$ & -0.672 & -4.202 & 0.120 & -5.61 & 0.00 & $>99$ \\
$x_{33}$ & -2.634 & -10.537 & 0.187 & -14.06 & 0.00 & $>99$ \\
\hline
\end{tabular}

The significance of the regression coefficients of the variables was described by $t$-test and $p$-values were used as tool to determine the significance of the variables [13], [14]. Thus based on the $t$ and $p$ values, one can predict the importance of the coefficients in the model. In general, as larger the $\mathrm{t}$ value and smaller the $p$ value, the regression coefficient corresponding to these values is more significant 
in the model [14]. From the Table II it can be noticed that based on $t$ and $p$ values interaction terms have least effect on the response. Therefore for further analysis interaction terms were neglected and linear + square model using Box-Behnken design was used, which is given in Table III. Table III shows that all the terms including linear and square terms, the significance level is greater than $90 \%$.

As all the regression coefficients have strong influence on the response and the polynomial regression equation for percentage conversion can be written in both uncoded and coded form as Eq. 2 and Eq. 3 respectively.

$$
\begin{aligned}
Y= & -388.954+8.898 X_{1}+12.624 X_{2}+33.470 X_{3}-0.061 X_{11} \\
& -0.672 X_{22}-2.634 X_{33} \\
& Y=93.513+1.813 X_{1}+6.349 X_{2}+14.256 X_{3}-1.52 X_{11} \\
& -4.201 X_{22}-10.536 X_{33}
\end{aligned}
$$

The analysis of variance (ANOVA) is the test to predict the statistical significance of the ratio of mean square variation due to regression and the square residual error [14]. ANOVA is presented in Table IV.

\begin{tabular}{lccccc}
\multicolumn{5}{c}{ TABLE IV: ANOVA RESULTS FOR PERCENTAGE CONVERSION } \\
\hline Source & $\begin{array}{c}\text { Degrees of } \\
\text { freedom } \\
(\text { d.f })\end{array}$ & $\begin{array}{c}\text { Sum of } \\
\text { squares } \\
(\mathrm{SS})\end{array}$ & $\begin{array}{c}\text { Mean } \\
\text { squares } \\
(\mathrm{MS})\end{array}$ & $F$ value & $P$ \\
\hline Regression & 6 & 2428.13 & 404.688 & 195.14 & 0.000 \\
Linear & 3 & 1974.66 & 238.757 & 115.13 & 0.000 \\
Square & 3 & 453.47 & 151.156 & 72.89 & 0.000 \\
Residual & 8 & 16.59 & 2.074 & & \\
Error & 3 & 15.05 & 2.508 & 3.26 & 0.254 \\
Lack of fit & 2 & 1.54 & 0.771 & & \\
Pure error & 14 & 2444.72 & & & \\
Total & & & &
\end{tabular}

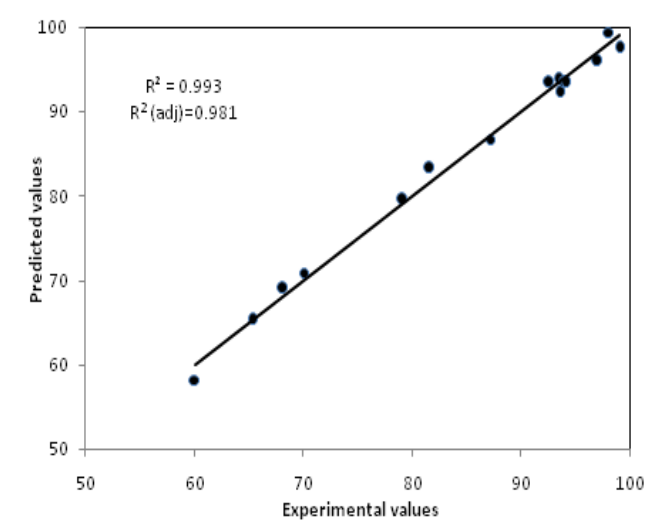

Fig. 1. Comparison of experimental with predicted values of $\%$ conversion

The $F$ value of regression (195.14) is higher than the tabulated value of 3.58 and that of lack of fit (3.26) is smaller than the tabulated value of 8.94 . This implies that the model Eq. 2 is good enough to explain all the variations in the response [9], [12]. The predicted values of the response (from model Eq. 2) are comparable with the experimental values as shown in Fig. 1 with R-sq of $99.3 \%$ and R-sq(adj) of $98.1 \%$. From the ANOVA table (Table IV) and Fig. 1, it can be indubitably state that the obtained model can be able to predict the response with good accuracy.

\section{B. Effect of Variable on Response}

The effect of variable on the responses can be visualized by generating response surface plots. The contour (2D) and surface (3D) plots are in this category and are used to predict the response for different values of the selected variables [13]. Figs. 2-4 are the contour and surface plots of percentage conversion of the reaction with regard to the variables such as temperature, the initial mole ratio of reactants and catalyst concentration. In all these plots response is plotted against two parameters keeping third the parameter constant, at high settings.
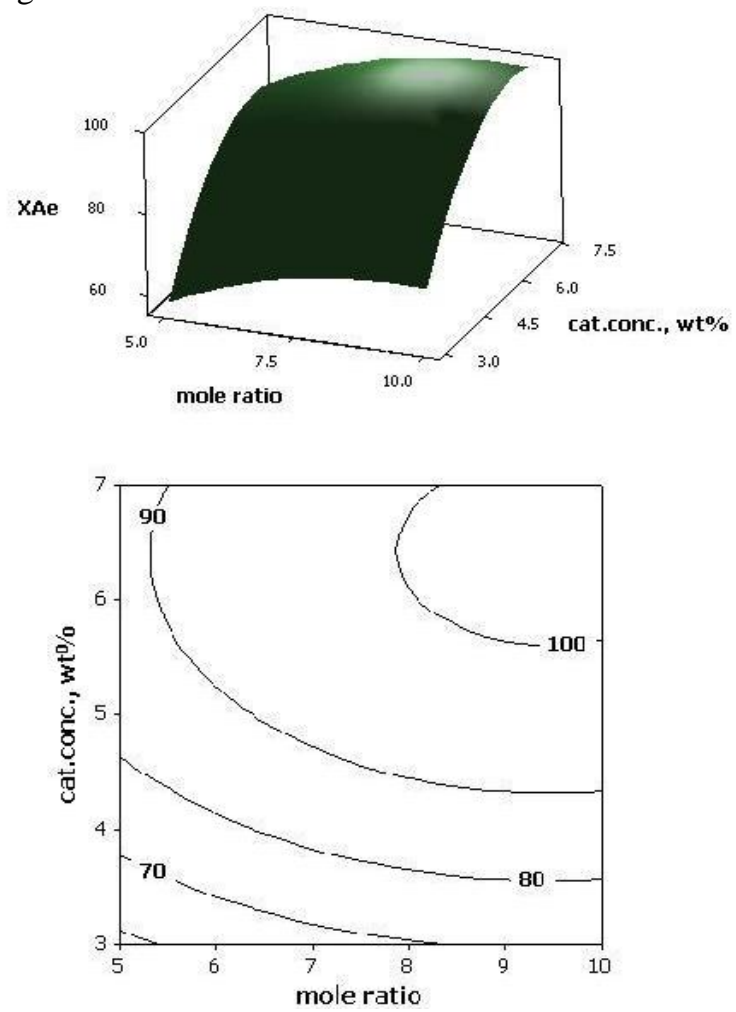

Fig. 2. Effect of catalyst concentration and mole ratio on conversion at temperature of $75^{\circ} \mathrm{C}$
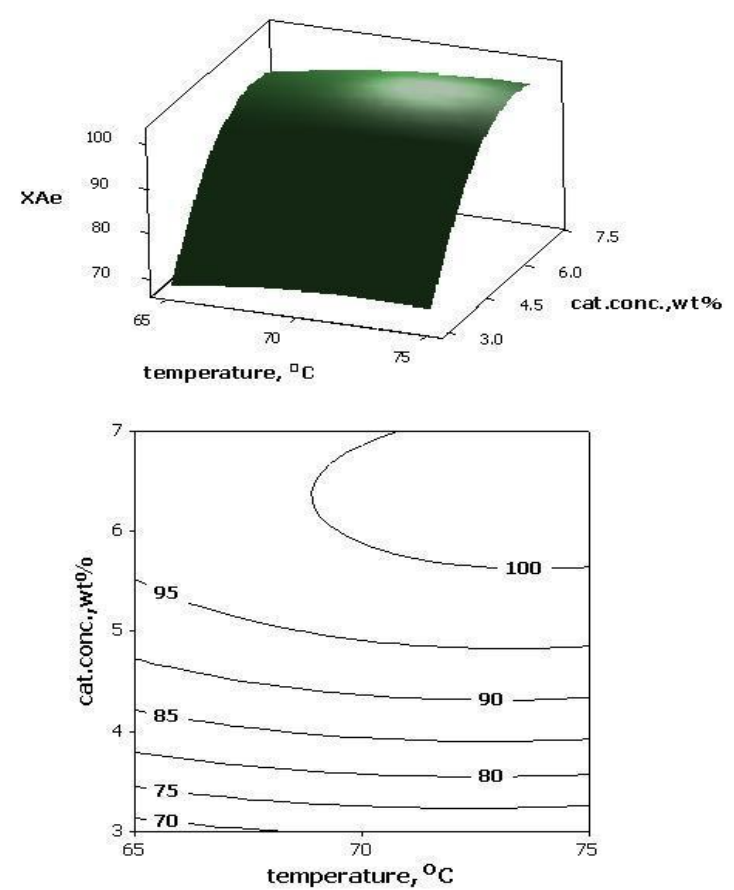

Fig. 3. Effect of catalyst concentration and temperature at initial mole ratio of reactants of 10 
Fig. 2 explains the relative effect of catalyst concentration vs. initial mole ratio of reactants at temperature of $75^{\circ} \mathrm{C}$. It can be seen that both catalyst concentration and mole ratio of reactants have key role in the enhancement of the conversion. The contour lines from 60 to 90 are closer and from 90 to 100 there is a wide gap between contour lines which indicates the demand of the high amount of catalyst and mole ratio for improvement in conversion.
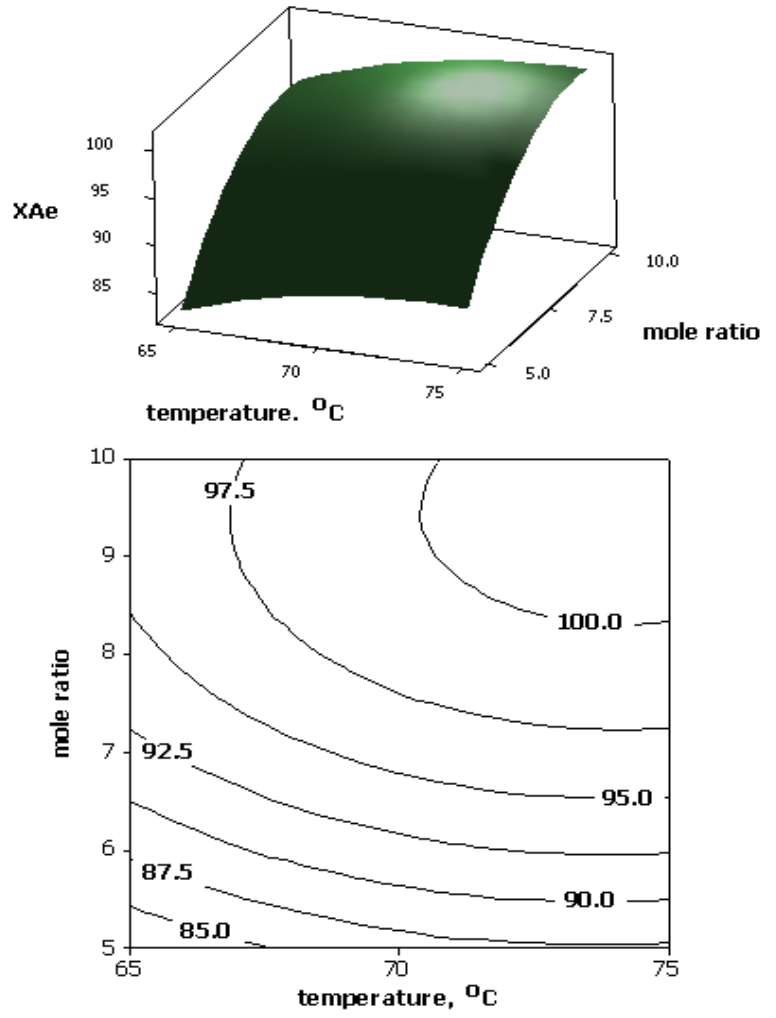

Fig. 4. Effect of initial mole ratio reactants and temperature at catalyst concentration of $7 w t \%$

The Figs. 2-4 demonstrates that all the response surfaces have the maximum points. The optimal condition giving the maximum percentage conversion of the present esterification reaction can be found out by Monte - Carlo optimization technique, according to the following equations:

$$
\begin{aligned}
& {\left[\frac{\partial Y}{\partial X_{1}}\right]_{X_{2} X_{3}}=0} \\
& {\left[\frac{\partial Y}{\partial X_{2}}\right]_{X_{1} X_{3}}=0} \\
& {\left[\frac{\partial Y}{\partial X_{3}}\right]_{X_{1} X_{2}}=0}
\end{aligned}
$$

The optimization of the non-linear Eq. 2 using the above technique produces the values of the variable for maximum conversion as temperature: $73^{\circ} \mathrm{C}$, the initial mole ratio of reactants as 9.4 and catalyst concentration as 6.4 weight $\%$. The response optimizer of this software reported the values of optimization as 74.09, 9.49 and 6.43 for temperature, the initial mole ratio of reactants and catalyst concentration respectively, which is in close agreement with Monte - Carlo method. This condition of maximum conversion is also experimentally verified.

\section{Reaction Kinetics}

The Esterification reaction of palmitic acid and ethanol in the presence of a homogeneous catalyst can be written as

$$
A+B \rightleftharpoons C+D
$$

where $A=$ Palmitic acid, $B=$ Ethyl alcohol, $C=$ Ethyl Palmitate and $D=$ water

Experiments were conducted on the basis of Box-Behnken design table and a few more experiments were conducted to obtain the kinetics of the reaction. Data were analyzed by integral method of analysis to obtain the order of reaction and rate constants. Analysis shows that data were fitting well for the first order reversible reaction as depicted in Fig. 5 and Fig. 6. For first order reversible reaction, on integral method of analysis leads to a rate expression as follows [15].

$$
-\ln \left(1-\left(\frac{X_{A}}{X_{A e}}\right)=k_{1} \frac{(M+1)}{M+X_{A e}} t\right.
$$

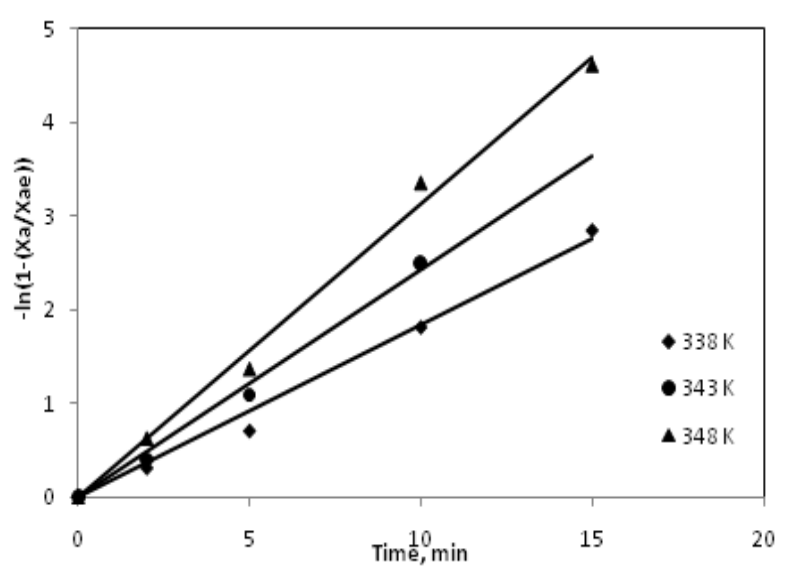

Fig. 5. Test of the rate equation, eq. (7) at $M=10$ and catalyst concentration of $5 \mathrm{wt} \%$.

Thus in Fig. 5 and Fig. $6-\ln \left(1-\left(X_{A} / X_{A e}\right)\right)$ is plotted against time at conditions of initial molar ratio of 10 and 7.5 and catalyst concentration of 5 and $3 w t \%$ respectively. The reaction rate constants $k_{1}$ and $k_{2}$ and equilibrium constants $K_{C}$ are estimated and listed in Table V. Arrhenius's law $k=k_{0} \exp (-E / R T)$ is used for calculating the activation energy of the reaction. Where $E$ is the activation energy, $k$ is the reaction rate constant and $k_{0}$ is the frequency factor. In Fig. $7-\ln (k)$ is plotted against $(1 / T)$, which gives a straight line with slope $(E / R)$. The forward and backward reaction activation energies were calculated as 56.7 and 4.79 $\mathrm{KJ} / \mathrm{Mol}$ respectively.

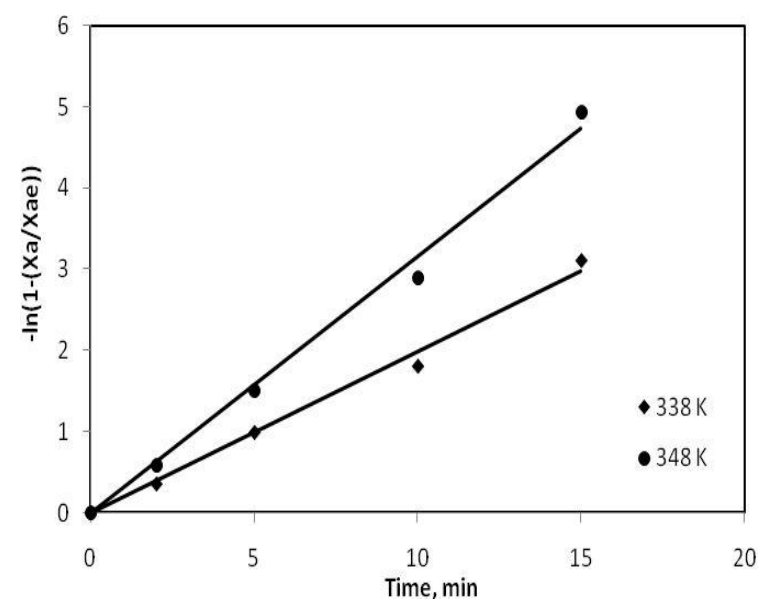

Fig. 6. Test of the rate equation, eq. (7) at $M=1$ and catalyst concentration of $5 \mathrm{wt} \%$. 
TABLE V: VALUES OF THE RATE AND EQUILIBRIUM CONSTANTS AT DIFFERENT TEMPERATURES

\begin{tabular}{cccc}
\hline Temperature,${ }^{\circ} \mathrm{C}$ & $k_{1} / \min$ & $k_{2} / \min$ & $K c$ \\
\hline 65 & 0.171 & 0.0119 & 14.38 \\
70 & 0.2299 & 0.0121 & 19 \\
75 & 0.312 & 0.0125 & 27.57 \\
\hline
\end{tabular}

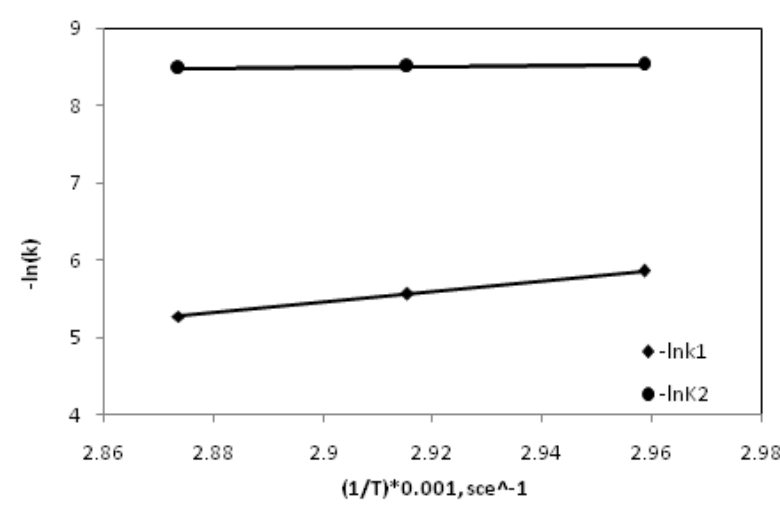

Fig. 7. Plot of $-\ln (k)$ vs. $1 / T$ for determination of activation energy.

\section{CONCLUSIONS}

A study of esterification of palmitic and ethanol in the presence of sulphuric acid as has been conducted. Box-Behnken response surface method was used to design the experiments. As per the demand of Box-Behnken design table, experiments were conducted and data were analyzed by the RSM, which provides a regression coefficient of the linear+ square model (Eq.2)and also found that effect of interaction between variables such as temperature, the initial mole ratio of reactants are very weak. The optimum values of the variables for achieving maximum conversion were found out by Monte - Carlo method and response surface optimizer and the results are in close agreement. The experimental data were subjected to integral method of to obtain the kinetics and identified that the reaction is reversible and first order in both forward and backward direction. The parameters such as $k_{1}, k_{2}$ and $K_{C}$ and activation energy were evaluated.

\section{REFERENCES}

[1] G. D. Yadav and P. H. Mehta, "Heterogeneous catalysis in esterification reactions," Ind. Eng. Chem., vol. 33, pp. 2198-2208, 1994.

[2] R. Ronnback, T. Salmi, A. Vuori, H. Haario, and J. Lehtonen, "Anna sundqvist and esko tirronen development of a kinetic model for the esterification of acetic acid with methanol in the presence of a homogeneous catalyst," Chemical Engineering Science, vol. 52, no. 19, pp. 3369-3381, 1997.

[3] I. L. Lucena, G. F. Silva, and F. A. N. Fernandes, "Biodiesel production by esterification of oleic acid with methanol using a water adsorption apparatus," Ind. Eng. Chem. Res., vol. 47, pp. 6885-6889, 2008.

[4] Y. Zhang, L. Ma, and J. C. Yang, "Kinetics of esterification of lactic acid with ethanol catalyzed by cation-exchange resins," Reactive and Functional Polymers, vol. 61, pp. 101-114, 2004.
[5] N. Lerkkasemsan, N. Abdoulmoumine, L. Achenie and F. Agblevor, "Mechanistic Modeling of palmitic acid esterification via heterogeneous catalysis," Ind. Eng. Chem. Res., vol. 50, pp. 1177-1186, 2011.

[6] M. L. Pisarello, B. Dalla Costa, G. Mendow, and C. A. Querini, "Esterification with ethanol to produce biodiesel from high acidity raw materials. Kinetic studies and analysis of secondary reactions," Fuel Processing Technology, vol. 91, pp. 1005-1014, 2010.

[7] D. Naydenov, H. Hasse, G. Maurer, and H.-J. Bart, "Esterification in ionic liquids with 1-alkyl -3-methylimidazolium cation and hydrogen sulfate anion: conversion and phase equilibrium," The Open Chemical Engineering Journal, vol. 3, pp. 17-26, 2009.

[8] D. C. Montgomery and G. C. Runger, Applied Statistics and Probability for Engineers, $4^{\text {th }}$ ed., John Willey and Sons, 2009.

[9] P. A. Soloman, C. A. Basha, M. Velan, N. Balasubramanian, and P. Maimuthu, "Augmentation of biodegradability of pulp and paper industry wastewater by electrochemical pre-treatment and optimization by RSM," Separation and Purification Technology, vol. 69, pp. 109-117, 2009.

[10] F. A. Pavan, Y. Gushikem, A. C. Mazzocato, S. L. P. Dias, and E. C. Lima, "Statistical design as a tool for optimizing the batch condition to methylene blue biosorption on yellow passion fruit and mandarin peels," Dyes and pigments, vol. 72, pp. 256-266, 2007.

[11] H. Kamali and H. S Ghaziaskar, "Pressurized hot water extraction of benzoic acid and phallic anhydride from petrochemical wastes using a modified supercritical fluid extractor and a central composite design for optimization," Journal of Supercritical Fluids, vol. 54, pp. 16-21, 2010.

[12] C. A. Basha, P. A. Soloman, M. Velan, N. Balasubramanian, and L. R. Kareem, "Participation of electrochemical steps in treating tannery wastewater," Ind. Eng. Chem, vol. 48, pp. 9786-9796, 2009.

[13] X. Zhang, R. J. Wang, X. X. Yang, and J. G. Yu, "Central composite experimental design applied to the catalytic aromatization of isophorone to 3, 5-xylenol," Chemometrices and Intelligent Laboratory Systems, vol. 89, pp. 45-50, 2007.

[14] K. Ravikumar, S.-H. Kim, and Y.-A. Son, "Design of experiments for the optimization and analysis of Berberine finishing of polyamide substrates," Dyes and Pigments, vol. 75, pp. 401-407, 2007.

[15] O. Levenspiel, Chemical Reaction Engineering, $3^{\text {rd }}$ Ed., John Willey and Sons, 1999.

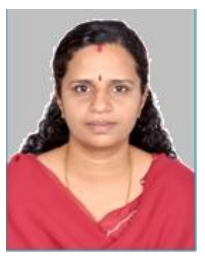

C. Beula is an assistant professor at the Department of Chemical Engineering, Government Engineering College, Calicut, Kerala and now deputed for $\mathrm{Ph}$. D programme at Indian Institute of Technology Madras Chennai, India. She has master degree in Chemical Engineering from Government Engineering College, Thrissur, Kerala. Her research is in the area of reaction engineering especially in the kinetics of reaction. Also interested in the study of ionic liquid, which is an emerging Eco-friendly catalyst for the reactions.

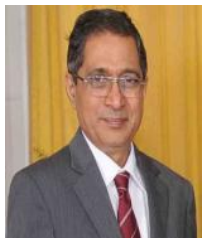

P.S. T. Sai is a professor and head of the Department of Chemical Engineering at the Indian Institute of Technology Madras. He has been actively involved in teaching and research for the past 25 years. His research interests include fluidization, reaction engineering and air pollution control. He has published over 70 research papers. His paper entitled 'Esterification of ethanol with sulfuric acid: A kinetic study' was awarded as the best paper published in the 12-month period in The Canadian Journal of Chemical Engineering in 2001. 